\title{
KULWA MALMING; MEDIA BELAJAR MANDIRI MATEMATIKA SEKOLAH KEJURUAN
}

\author{
K. Sutame ${ }^{1}$ \\ 1. SMK NEGERI 3 Banjarmasin \\ ahsanul1977@mail.com
}

\begin{abstract}
ABSTRAK
Makalah ini bertujuan memberikan gambaran teknis berkaitan upaya menarik simpati siswa di SMK Negeri 3 Banjarmasin terhadap pembelajaran matematika melalui sentuhan teknologi informasi. Makalah ini berisikan kajian teori tentang membangun pembelajaran yang menyenangkan dengan memanfaatkan waktu luang siswa untuk menguatkan konsep-konsep matematika dengan dipandupadankan dengan teknologi informasi berupa aplikasi pesan. Metode penulisan adalah deskripsi berdasarkan pengalaman pemakalah di SMK Negeri 3 Banjarmasin. Adanya pelibatan teknologi dalam pembelajaran, sudah tak dapat dihindari dan tidak dapat dipungkiri mampu memberikan sumbangsih bagi pembelajaran matematika baik dalam meningkatkan prestasi maupun minat siswa. Davis dan Tearle (1999) (Dalam Syed Noor-Ul-Amin) menyebutkan TIK berpotensi memberikan inovasi, akselerasi, pengayaan dan memperkuat keterampilan untuk memotivasi dan meningkatan pembelajaran pada siswa serta membantu menghubungkan dunia kerja dengan sekolah. Adanya TIK memberikan kesempatan siswa dan guru untuk melaksanakan pembelajaran dimana saja, kapan saja dan dengan siapa saja. Salah satu varian TIK adalah pesan singkat berbasis smartphone yakni aplikasi WhatsApp. Fitur-fitur yang dimiliki oleh Whatsapp menjadikan aplikasi ini akun wajib yang dimiliki oleh siswa dan guru. Oleh pemakalah aplikasi ini menjadi jargon pembelajaran tambahan matematika yang menarik yakni Kulwa Malming (Kuliah via WhatsApp Malam Minggu). Aktivitas belajar mandiri yang dilakukan adalah diskusi yang berfungsi menguatkan konsep matematika dilengkapi dengan presensi kehadiran Kulwa Malming. Adanya keunggulan-keunggulan pada Kulwa Malming diyakini mampu mefasilitasi pembelajaran matemtika yang menarik dalam meningkatkan kualitas pembelajaran di sekolah kejuruan.
\end{abstract}

Kata Kunci: Kulwa Malming, Belajar Mandiri, Media Belajar

\section{PENDAHULUAN}

Adanya perubahan paradigma pola manusia memenuhi kebutuhannya dengan melibatkan teknologi informasi, memaksa sistem yang lainya mendigitalisasi diri. Era revolusi industri secara langsung atau tak langsung juga merambah dunia pendidikan. Penggunaan teknologi informasi akhirnya menjadi sebuah gaya hidup 
dan peradaban baru. Dengan hanya mengandalkan gadget ditangan, manusia dapat memenuhi seluruh kebutuhannya dari perkara kenutuhan primer hingga kebutuhan tersier. Wajar penggunaan internet di Indonesiaa merupak yang paling tertinggi. Jika disorot lebih tajam lagi berkaitan dengan penggunaan internet di Indonesia, maka akan ditemukan data-data yang menakjubkan. Misalnya data pengguna internet di Indonesia yang disurvei oleh Assosiasi Pengguna Jasa Internet Indonesia (APJII) tahun 2018. Berikut hasil temuan APJII.

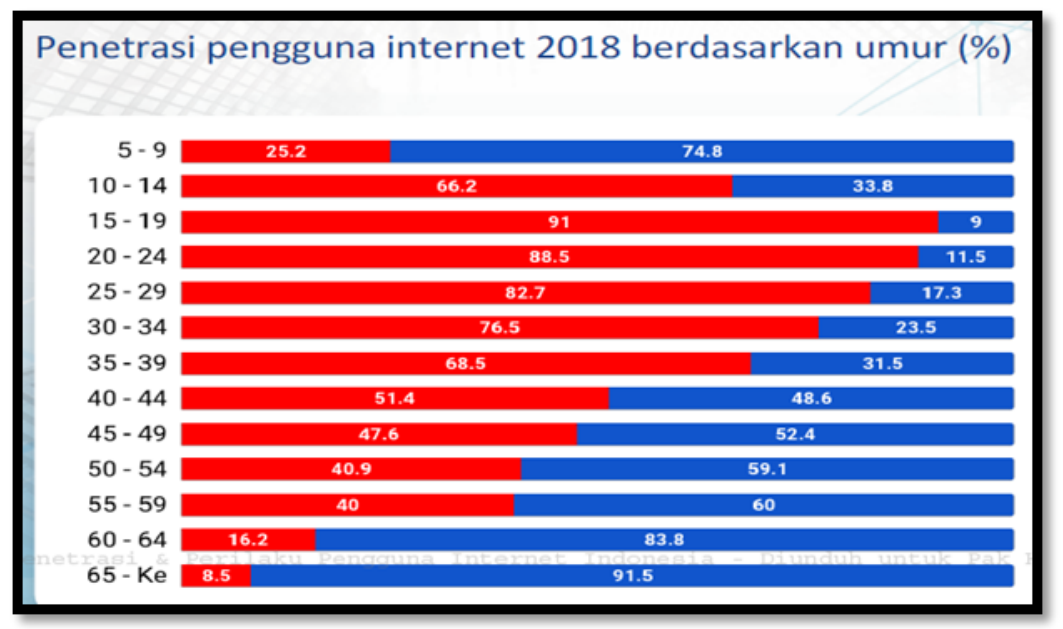

Gambar 1. Pengguna Internet Berdasarkan Umur di Indonesia

Berdasarkan data yang dikeluarkan oleh APJII (2018) nampak bahwa pengguna jasa internet pada pada usia 15 tahun sampai dengan 19 tahun sebanyak 91\%. Artinya hanya $9 \%$ usia 15 tahun hingga 19 tahun yang tidak menggunakan internet. Jika dilihat seluruh kelompok umur, interval pada usia 15 tahun samapi dengan 19 tahun yang paling banyak menggunakan jasa internet. Selanjutnya diantara usia 15 - 19 tahun yang berstatus sebagai pelajar, APJII juga memiliki data persentase pengguna internet. Berikut dara yang dimaksud.

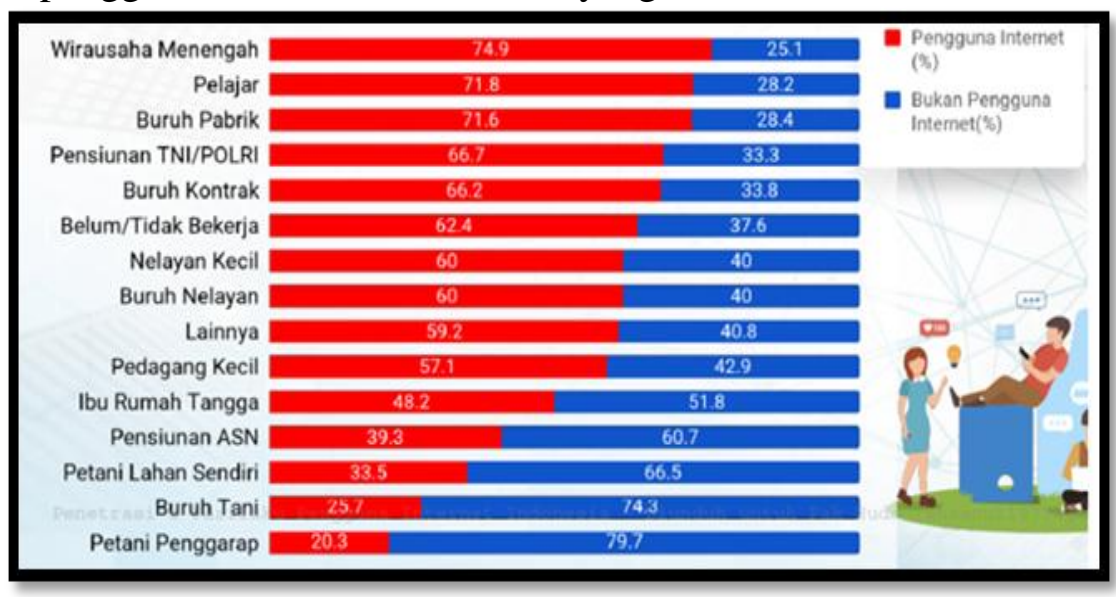

Gambar 2. Pengguna Internet Berdasarkan Profesi di Indonesia 
Penggunaan internet dikalangan pelajar sangat tinggi, yakni sekitar 71,8\%. Artinya hanya ada sekitar $25,1 \%$ pelajar yang tidak menggunakan internet. Aktivitas internet yang dilakukan oleh pengguna internet Indonesia bervariasi dari sekedar mencari informasi hingga mencari pekerjaan. Dalam aktivitas penggunaan jenis aplikasi ternyata aplikasi lewat pesan lebih dominan. Berikut potret alasan pengguna internet yang diungkap oleh APJI (2018).

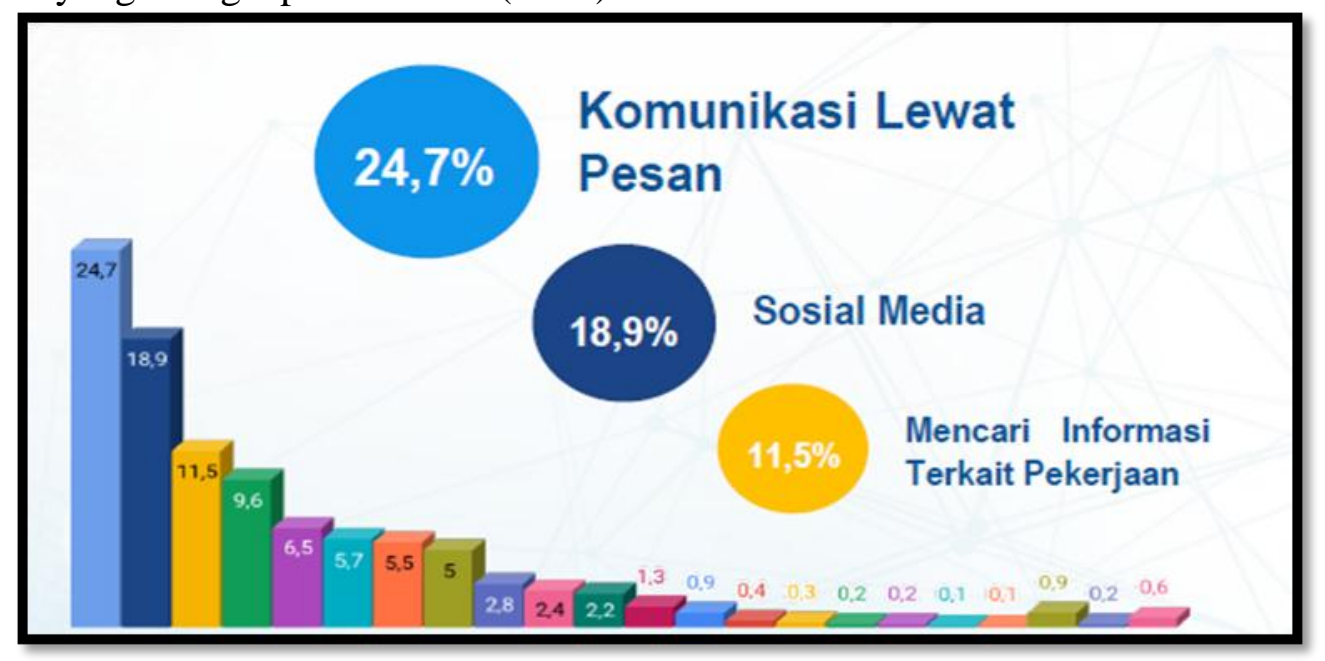

Gambar 3. Perilaku Pengguna Internet Indonesia.

Berdasarkan data di atas, pengguna internet termasuk pelajar paling banyak menggunakan komunikasi lewat pesan. Artinya ada potensi penggunaan internet dengan menggunakan aplikasi pesan dimanfartkan untuk pembelajaran.

Padahal melalui penggunaan ITC dalam manajemen pembelajaran di sekolah sangat membantu dan mampu secara signifikan memberikan sumbangsih terhadap kemajuan pembelajaran di sekolah dengan masing-masing tugas pokok dan fungsinya. Menurut Davis dan Tearle (1999) (Dalam Syed Noor-Ul-Amin) menyebutkan, "ICTs have the potential to innovate, accelerate,enrich, and deepen skills, to motivate and engage students, to help relate school experience to work practices, ......". TIK berpotensi memberikan inovasi, akselerasi, pengayaan dan memperkuat keterampilan untuk memotivasi dan meningkatan pembelajaran pada siswa serta membantu menghubungkan dunia kerja dengan sekolah.

Pembelajaran matematika di Sekolah kejuruan berada dalam kelompok mata pelajaran adatif (jika mengacu pada kurikulum KTSP) atau masuk kelompok Muatan Nasional (jika mengacu pada kurikulum 2013 revisi). Matematika masih menjadi mata pelajaran yang paling tidak sukai oleh siswa di sekolah kejuruan. Salah satu indikator tersebut dapat dilihat dari raihan yang dicapai oleh siswa kejuruan pada saat UNBK tahun 2018/2019. Berikut hasil Penilaian Pendidikan Kemdikbud tahun 2019 tentang hasil UNBK sekolah kejuruan negeri dan swasta nasional. 


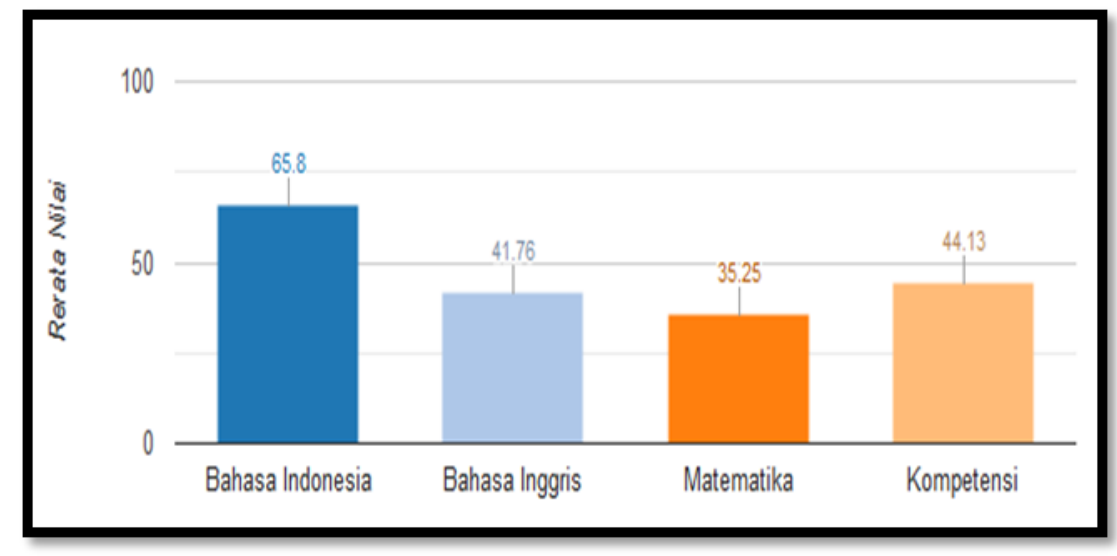

Gambar 4. Hasil UNBK SMK Negeri/Swasta 2019.

Sajian statistik di atas, jelas menunjukan bahwa mata pelajaran matematika masih menjadi momok bagi siswa kejuruan. Tugas guru matematika di SMK kejuruan adalah berupaya menyajikan pembelajaran matematika yang menyenangkan siswa. Secara psikologis, jika siswa menyenangi sesuatu maka siswa tersebut akan melakukan sesuatu dengan suka cita. Menurut falsafah Jawa, cinta/kesukaan itu akan muncul akibat intensitas pertemuan. "Witing Tresno Jalaran Soko Kulino" adalah sebuah ungkapan dalam bahasa Jawa, yang kalau diartikan dalam Bahasa Indonesia artinya menjadi "Cinta tumbuh karena terbiasa". Memang kalau dipahami maksudnya, akan bisa dimengerti bahwa cinta itu akan bisa tumbuh karena terbiasa. Terbiasa bertemu, terbiasa bersama-sama. Kalaupun mungkin pada awalnya cinta itu belum tumbuh, tetapi karena sering bertemu dan sering bersama-sama akhirnya cinta itupun mulai tumbuh. Jika falsafah Jawa tersebut diimplementasikan dalam pembelajaran matematika maka ditemukan rumusan yakni jika sering beriteraksi dengan pembelajaran matematika maka minat/cinta matematika akan tumbuh.

Pertanyaan selanjutnya bagaimana menambah intensitas pertemuan pembelajaran matemtika? Tentu bukan menambah jam pelajaran matematika. Maka kata kunci dalam hal ini adalah melibatkan teknologi informasi dalam pembelajaran non formal (diluar jam formal pembelajaran di kelas). Berdasarkan fakta pemanfaatan internet disimpulkan bahwa siswa sangat femiliar dengan aplikasi pesan singkat yakni aplikasi Whatsaap. Jadi guru memanfaatkan waktu luang siswa untuk pembelajaran matematika secara non formal melalui aplikasi pesan yakni whatsaap untuk mendiskusikan konsep-konsep matematika di sekolah kejuruan. Tujuan dari penulisan makalah ini adalah untuk memberikan gambaran teknis tentang pemanfaatan aplikasi whatsaap untuk pembelajaran matematika untuk pembelajaran mandiri.

\section{METODE PENELITIAN}

Penulisan makalah ini menggunakan pendekatan bersifat kualitatif dengan metode deskriptif analitis. Metode tersebut merupakan cara yang digunakan untuk 
mendeskripsikan dan menggambarkan secara faktual dan akurat mengenai fakta-fakta yang ada serta hubungan antara fenomena yang ditelitinya. Metode deskriptif analitis dari fakta yang diperoleh diharapkan dapat menemukan kecenderungan atau kemungkinan adanya fenomena hasil pembelajaran.

Objek dari penulisan makalah ini adalah siswa-siswi SMK Negeri 3 Banjarmasin yang didasarkan pada pengalaman dari penulis yang merupakan Guru di SMK Negeri 3 Banjarmasin. tersebut.

Ada beberapa hal yang perlu diperhatikan saat merancang Kulwa Malming

1. Pastikan siswa dan fasilitaor menggunakan perangkat untuk akses aplikasi WhatsApp tersebut yakni baik berupa smartphone ataupun laptop.

2. Pastikan smartphone atau laptop telah terkoneksi dengan internet

3. Sifat dari Kulwa Malming adalah menguatkan konsep yang telah didapat dari tatap muka. Artinya kulwa malming adalah tindak lanjut belajar mandiri setelah belajaran tatap muka langsung.

4. Sebelum dilaksanakan Kulwa Malming, pastikan telah terjadi kesepakatan tentang waktu dari Kulwa Malming.

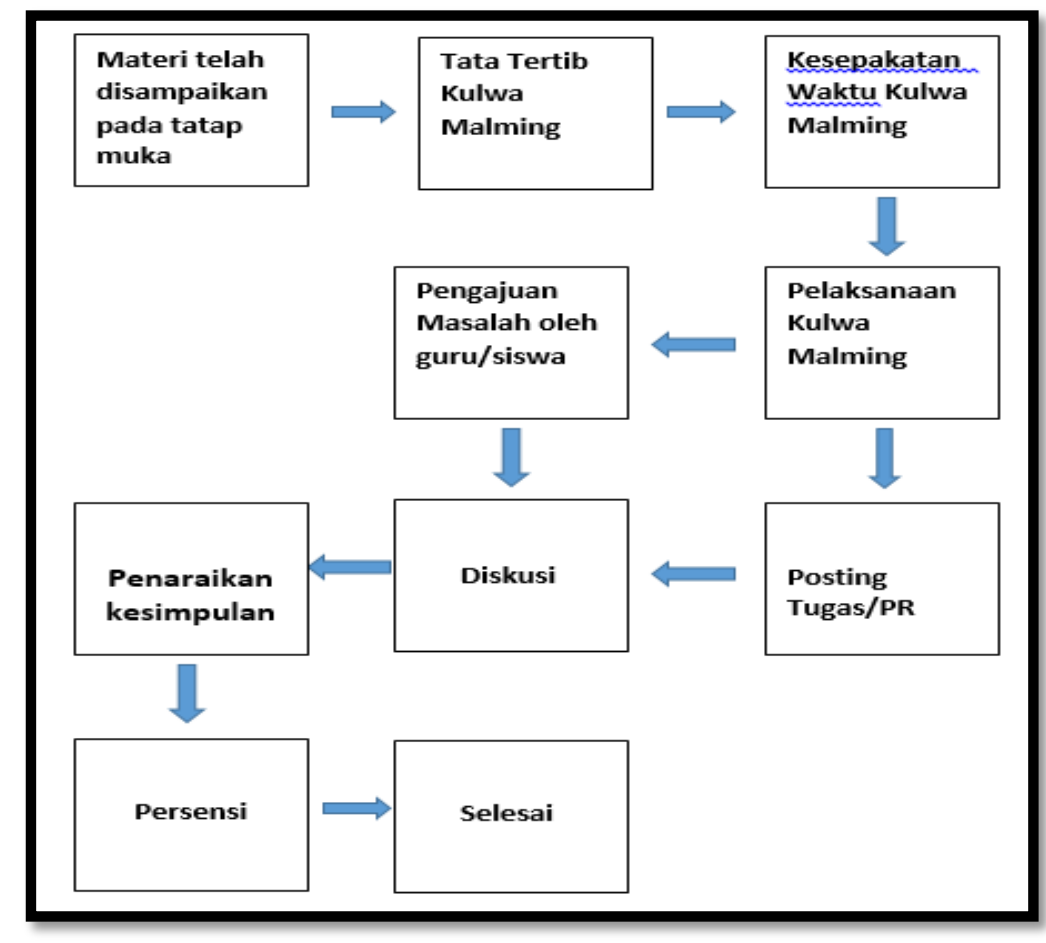

Gambar 5. Desain Kulwa Malming.

Materi tatap muka telah selesai dilaksanakan tetapi masih menyisakan soalsoal latihan yang berkaitan dengan persamaan kuadrat. Terlebih dahulu guru telah membuat grup di wahtsApp yang beranggotakan seluruh siswa dan aguru menjadi admin grup tersebut. Sebelum melaksanakan Kulwa Malming, terlebih dahulu guru 
meposting tentang aturan dari Kulwa Malming di grup. Berikut contoh tata tertib yang dibuat oleh guru.

\section{aturan kuliah whatshaap matematika \\ 1. peserta sholat isya terlebih dahulu \\ 2. membaca materi dengan seksama}

3. berdiskusi di grup WA tentang hal yang tidak dipaham

4. ketika materi sudah dipahami, silakan mengerjakan soal latihan di classroom $17: 07 \checkmark$

5. absen KulWa diisi ketika ingin menyelesaikan diskusi.

6. absen kulwa akan diberikan linknya di grup WA

7. silakan screen shoot (SS) bukti keaktifan di grup WA selanjutnya akan diupload ketika mengisi absen kulwa.

8. ingat absen kulwa diisi ketika hendak keluar dari diskusi. jangan lupa SS bukti aktivitas anda di grup WA.

\section{Gambar 6. Tata Tertib Kulwa Malming}

\section{HASIL DAN PEMBAHASAN}

\section{A. Hasil}

Guru dan siswa menyapakati pertemuan Kulwa Malming yang berkaitan dengan durasi waktu Kulwa Malming. Sealanjutnya diskusi dimulai. Salah satu siswa meposting hasil pengerjaan latihan di grup. Berikut tampilannya.

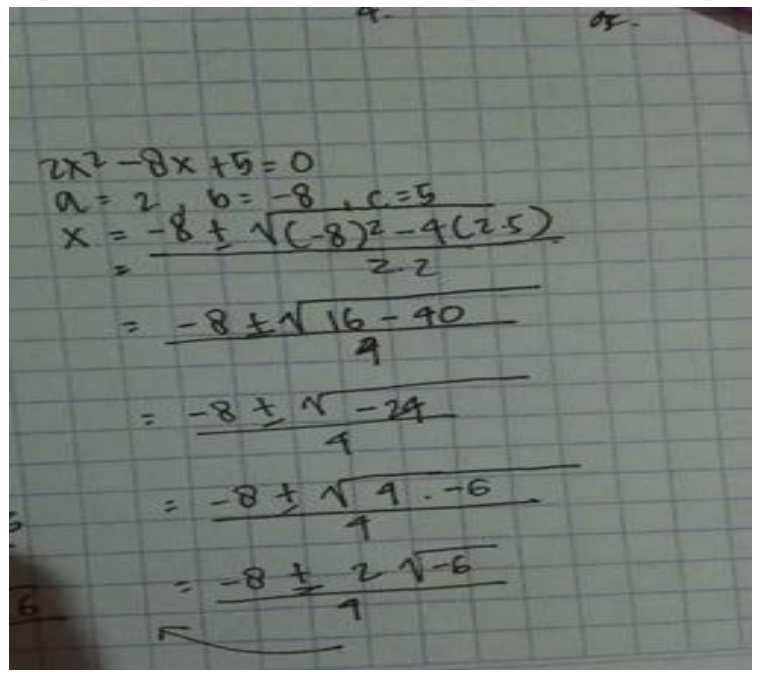

Gambar 7. Posting Hasil Pengerjaan Latihan Soal Oleh Siswa 
$+62819-4588-7685$ rale

$x=\frac{-8+2 \sqrt{6}}{14} \quad$ atau $x=\frac{-x^{2}-2 \sqrt{6}}{x}$

$=\sqrt{6} 2 \sqrt{6} \quad x=-4 \sqrt{6}$

jati akar - akar $\operatorname{gan} 2 x^{2}-8 x+5=0$

adatah $2 \sqrt{-6}$ atalu $-9 \sqrt{-6}$

mohon jawabannya pak, kalau $b=-8$ seperti di soal no 2 ketika di masukkan ke rumus $-b \pm \sqrt{ } b 2-4 a c$ apakah jadi +8 ? atau tetap -8 ?

+62 831-5011-8157 Nur Halifah

Gambar 8. Diskusi Antara Sesama Siswa

$+62831-5011-8157 \sim$ Nur Halifah

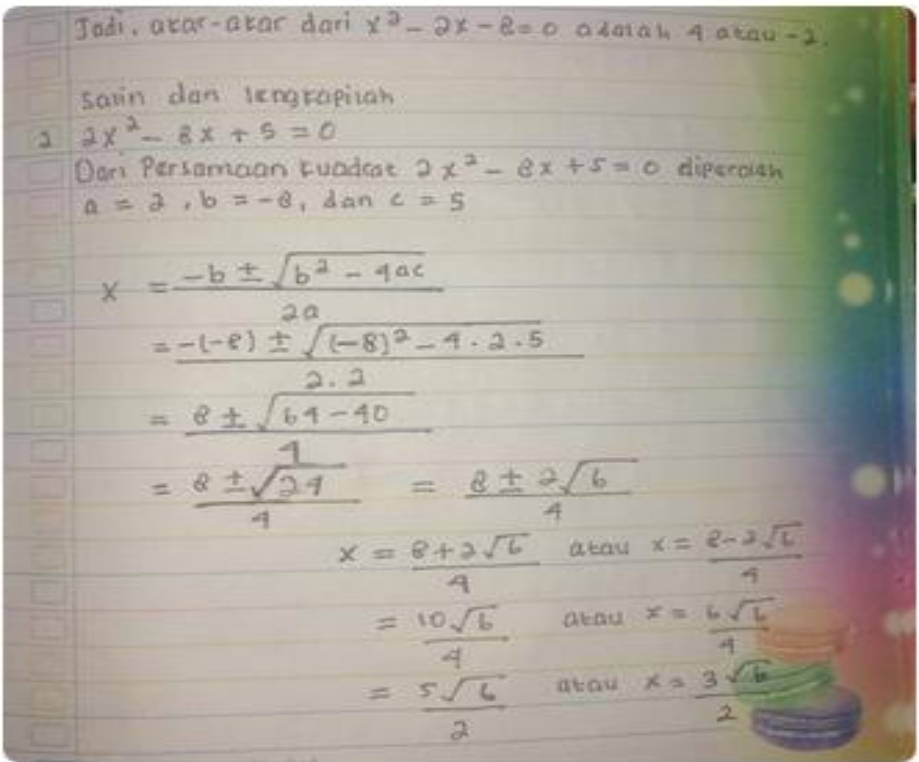

UIn kyani

Gambar 9. Hasil Pengerjaan Oleh Siswa Yang Lain 


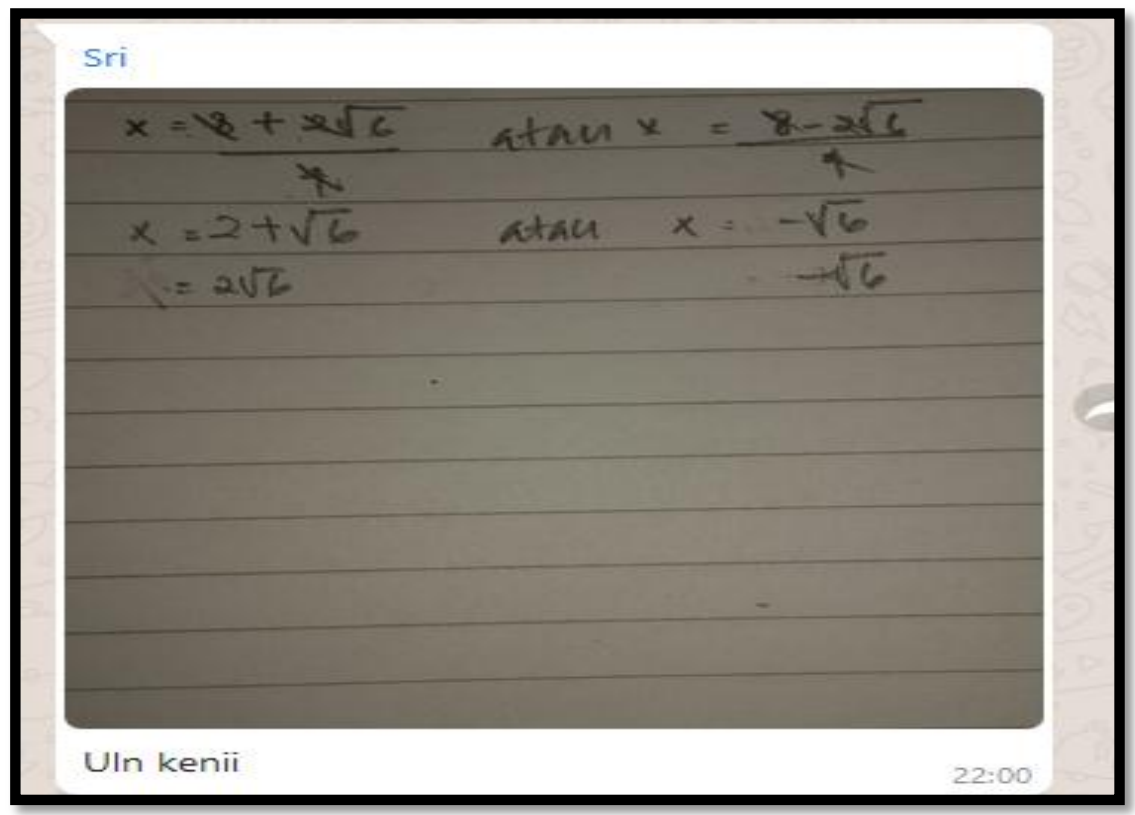

Gambar10. Hasil Pengerjaan Siswa Yang Lainnya

+62 822-5225-6142 AnnisaPutri

+62 819-4588-7685 ale

Karena xnya kda betulis $\mathrm{X} 1 \mathrm{kah}$ pak?

yg tambah nya tuh kynya le

+62 831-5011-8157 Nur Halifah

You

ol Sri, sama2 dibagi 2, jadi berapa?

$4+1$ akar 6 per 2 kah pa

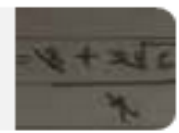

+62 852-1957-3292 Andieny

You

Benar, punya Sri hampir benar....

Punua srie brrti tetap $2+\sqrt{ } 6$ lah pak

Gambar 11. Diskusi Antar Siswa. 
+62 819-4588-7685 ale

(+62 822-5225-6142 AnnisaPutri

bapak kenpa harus dibagi 2 pa?

Karena $8 \pm 2 \sqrt{6}$ itu kada sejenis. Jadi kada kawa dijumlahkan, dibagi karena 8,4, dan 2 tu kawanya sama-sama dibagi 2 aja

+62 852-1957-3292 Andieny
Ouhnggin $22: 22$

Gambar12. Guru Menjadi Fasilitator Saat Diskusi

\section{Absen KulWA (Kuliah Via WhatsApp)}

Deskripsi formulit

Nama Siswa *

Teks jawaban singkat

Kelas *

Teks jawaban singkat

Status Kehadiran *

1. Menyimak Saja

2. Menyimak, aktif bertanya

3. Menyimak, aktif menjawab pertanyaan

4. Menyimak, aktif bertanya, aktif menjawab pertanyaan

Upload Bukti Kehadiran *

土 Tambahkan file

Gambar 13. Presensi Kulwa Malming 


\section{B. Pembahasan}

Kulwa Malming merupakan akronim dari Kuliah via WhatsApp sedangkan Malming adalah akronim dari Malam minggu. Maksud dari Kulwa Malming adalah pembelajaran mandiri dengan media pesan singkat melalui aplikasi WhatsApp yang dilaksnakan pada malam minggu atau sabtu malam. Pembelajaran mandiri ini dilakukan dengan tujuan untuk memperkuat konsep yang telah diberikan oleh guru pada tatapmuka secara formal di kelas. Pembelajaran yang dilakukan berbasis konstruktisme. Pembelajaran ini mememrlukan waktu yang cukup karena siswa yang membangun konsep secara mandiri.

Guru hanya sebagai fasilitator. Saat diskusi, guru benar-benara menjadi fasilitator serta terus memotivasi siswa agar terus mencoba dengan konsep yang telah diberikan. Setelah siswa selesai melakukan diskusi, selanjutnya siswa melakukan refleksi untuk menarik kesimpulan dari diskusi yang telah dilakukan.Setelah siswa selesai melakukan penarikan kesimpulan, selanjutnya siswa melakukan presensi kehadiran Kulwa Malming secara online. Presensi kehadiran secara online dibuat dengan menggunakan aplikasi google form dari google. Dipilihnya belajar mandiri dengan media whatsApp adalah sebagai terobosan atas permasalahan terbatasan waktu tatap muka langsung.

Seiring dengan perkembangan jaman dan kecanggihan teknologi dan informasi, pengalaman belajar siswa dapat diperoleh melalui internet dengan berbagai variannya misalnya pesan singkat WhatsApp. Bermacam-macamnya media pembelajaran dapat dipilih oleh guru dengan memperhatikan kriteria kebutuhan dan tujuan pembelajaran. (1) tujuan pembelajaran; (2) kesesuai dengan materi pembelajaran; (3) karakteristik siswa; (4) gaya belajar siswa (audtif, visual serta kinestika); (5) lingkungan; (|6) kesediaan fasilitas pendukung.

SMK yang merupakan sekolah yang mencetak peserta didik dengan memiliki keterampilan. Hal ini sesuai dengan prinsip link and macth. Link and macth diartikan sebagai upaya mengarahkan lembaga pendidikan (SMK) untuk mengeluarkan output yang tidak sekedar tempat mengembangkan kemampuan dan keahliannya melainkan dapat memenuhi kebutuhan masyarakat.

Para pakar pendidikan telah memberikan penjelasan bahwa kurikulum yang ideal untuk pendidikan kejuruan harus memiliki fitur berikut dan didukung langkahlangkah: (1) struktur kurikulum yang fleksibel, (2) bahan ajar yang menarik, (3) pendekatan pengajaran yang beragam, (4) menggunakan mekanisme penilaian berbasis kompetensi, dan (5) akses yang mudah untuk mengikuti program pelatihan guru lanjutan. Di samping itu proses belajar mengajar hendaklah dilakukan dengan menitikberatkan pada: (1) fleksibilitas, (2) kemampuan beradaptasi, dan (3) pencapaian kompetensi peserta didik. Menurut Apri Nuryati, pembelajaran di SMK mutlak melibatkan intervensi TIK dalam pembelajarannya. Intervensi TIK dalam pembelajaran SMK diharapkan dapat memaksimal pembelajaran itu sendiri. 


\section{SIMPULAN}

Merancang pembelajaran mandiri dengan menggunakan media belajar whatsApp dapat mengikuti langkah-langkah berikut:

1. Memastikan telah dilakukan pembelajaran secara langsung yakni melalui tatap muka langsung, selanjutnya diperkuat dengan belajar mandiri oleh siswa.

2. Guru membuat tata tertib diskusi Kulwa Malming yang dipostiing di grup WhatsApp.

3. Guru dan siswa membuat kesepatan berkaitan dengan waktu pelaksanaan Kulwa Malming.

4. Siswa melakukan diskusi dengan rekan yang lain sedangkan guru menjadi fasilitator pada diskusi lewat Kulwa Malming.

5. Siswa dibantu guru membuat kesimpulan Kulwa Malming

6. Siswa mengisi presensi secara online yang telah disiapkan oleh guru.

\section{DAFTAR RUJUKAN}

Abu Gazi. (2010). Faktor-faktor yang Mempengaruhi Kemandirian Belajar. Diunduh melaluihttps://www.academia.edu/7104246/Faktorfaktor_yang_Mempengaruhi _Kemandirian_Belajar_29th_October_2010_0_Comments_71.

Christina Ismaniati, (-----). Penggunaan Teknologi Informasi dan Komunikasi dalam PeningkatanKualitasPembelajaran.Diunduhmelalaui.http://staff.uny.ac.id/sites/ default/files/penelitian/Dr.\%20Christina\%20Ismaniati,\%20M.Pd./Penggunaan \%20Teknologi\%20Informasi\%20dan\%20komunikasi\%20dalam\%20peningkat an\%20kualitas\%20pembelajaran.pdf_Pengunjung_Faktorfaktor_yang_Mempe ngaruhi_Kemandirian_Belajar_1.

Direktorat Pendidikan Menengah Kejuruan. (1994). Konsep Sistem Ganda. Departemen Pendidikan dan Kebudayaan, Jakarta.

Jalinus Nizwardi. (2016). Media dan Sumber Pembelajaran. Kencana: Jakarata.

Kepmendikbud. (1997). Penyelenggaraan Sistem Pendidikan Ganda pada SMK. Depdikbud.

Muhammad Dzaky Firdaus. (2018). Pengembangan Aplikasi Pesan Instan WhatsApp dalam Pembelajaran Microteaching sebagai Media Alat Bantu Belajar Mandiri Mahasiswa Pendidikan Teknik Otomotif Universitas Negeri Yogyakarta. Skripsi: Fakultas Teknik UNY.

Riza Anugrah Putra, dkk (2017). Penerapan Metode Pembelajaran Mandiri dalam Meningkatkan Hasil Belajar Peserta Didik. Jurnal Pendidikan Luar Sekolah. Vol I: 23-36. 